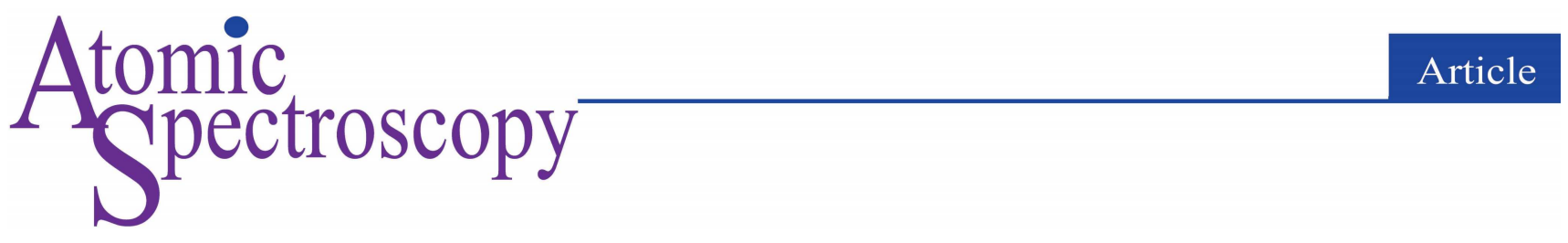

\title{
Leaching of Gallium from Coal Fly Ash, Alumina and Sediment Samples with an Acid Mixture for its Determination by ICP-OES
}

\author{
A.C. Sahayam, ${ }^{\mathrm{a}, \mathrm{b}, *}$ G. Venkateswarlu, ${ }^{\mathrm{a}}$ and S. Thangavel ${ }^{\mathrm{a}}$ \\ ${ }^{a}$ National Centre for Compositional Characterisation of Materials (NCCCM), Bhabha Atomic Research Centre (BARC), ECIL (P.O.), Hyderabad 500062, \\ India \\ ${ }^{\text {b } H o m i ~ B h a b h a ~ N a t i o n a l ~ I n s t i t u t e ~(H B N I), ~ M u m b a i, ~ I n d i a ~}$
}

Received: September 25, 2020; Revised: October 24, 2020; Accepted: October 24, 2020; Available online: October 29, 2020

DOI: $10.46770 / A S .2020 .183$

ABSTRACT: Leaching of gallium (Ga) from coal fly ash, alumina and sediment is reported for its determination by inductively coupled plasma optical emission spectrometry (ICP-OES). A mixture of acids $\left(\mathrm{H}_{2} \mathrm{SO}_{4}, \mathrm{HNO}_{3}\right.$ and $\left.\mathrm{HF}\right)$ was used for the leaching process which was carried out overnight at room temperature or heated for $1 \mathrm{~h}$ on a hot plate. HF is essential for the quantitative recovery of $\mathrm{Ga}$ from coal fly ash. Leaching with either $\mathrm{HCl}$ or $\mathrm{HNO}_{3}$ in combination with $\mathrm{HF}$ also yielded quantitative recoveries of $\mathrm{Ga}$ from coal fly ash, but not from other matrices. After leaching, $\mathrm{HF}$ and $\mathrm{HNO}_{3}$ were evaporated and $\mathrm{HCl}$ was added to the acid leach before dilution for analysis. When mixed acid leaching was employed, leaching of Ga was $92-102 \%$. For accuracy, the method was applied to a sediment sample, a candidate material prepared as the in-house CRM, and the values obtained were well within the uncertainty reported. The present procedure was validated using the solvent extraction method. The values by the two methods were in close agreement according to the Student's t-test with a confidence level of $95 \%$. The limit of detection was $0.45 \mathrm{mg} \mathrm{Kg}^{-1}$. The analytical methodology was applied for the determination of Ga in three coal fly ash samples, two from thermal power plants and a NIST CRM 1633b (not certified for $\mathrm{Ga}$ ) as well as an alumina sample from an aluminum industry facility. A red mud sample, by-product of Bayer's process of aluminum extraction, was also analyzed using $\mathrm{HCl} / \mathrm{HF}$ and $\mathrm{HNO}_{3} / \mathrm{HF}$ leach.

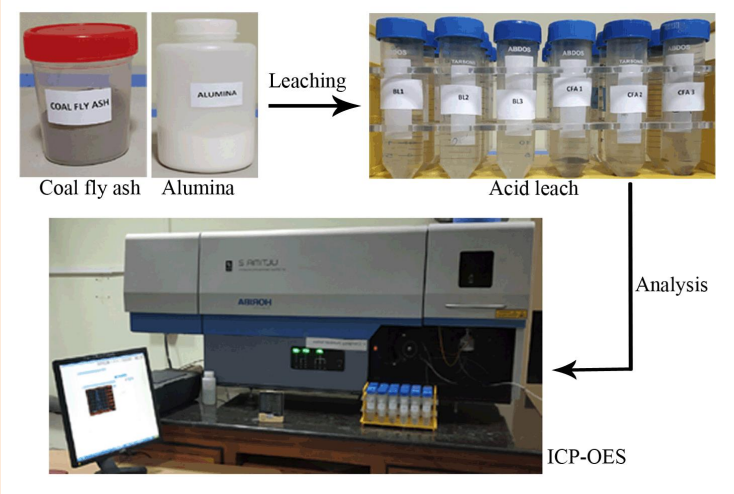

\section{INTRODUCTION}

Gallium (Ga) is a chemical element that is relatively rare and has been used largely in the electronics industry. Ga does not have its own ore and in nature occurs in trace amounts as $\mathrm{Ga}(\mathrm{III})$ compounds, principally in bauxite (aluminum matrix) and zinc ores. $^{1,2}$ Due to the limited natural resources and the growing demand, there may be global competition for the production of $\mathrm{Ga}$ and hence, alternate resources need to be evaluated for economic reasons. ${ }^{3} \mathrm{Ga}$ can also be found in coal, with approximately 10 million tons of Ga contained in the coal resources on earth. ${ }^{4}$ The content of Ga in coal varies regionally. Coal fly ash is a solid residue obtained after combustion of the coal in thermal power plants. This by-product is toxic due to the presence of organic and

inorganic constituents of varying compositions depending on the grade of coal. Production of coal fly ash is very high, considering that $40 \%$ of the electrical power is generated through combustion of coal globally. ${ }^{5}$ India is among the top three countries in the world that utilizes coal-fired power plants. ${ }^{6}$ The majority of coal fly ash is unutilized and stored in ash ponds and surface impounds, increasing the threat of contamination to both underground water and also air. Constituents of coal fly ash can be extracted based on their utility and also commercial value. Ga is one such constituent and due to its efficient optical transitions and also electron mobility, it is recognized as a very important component in the preparation of compound semiconductors used in photovoltaic cells. ${ }^{7}$ Prior to engaging in large-scale recovery, the coal fly ash samples need to be screened for their Ga content to establish the commercial value 
for extraction. A simple analytical methodology is needed to carry out such screening. Another important source of Ga is bauxite, an aluminum ore. Gallium is extracted from the by-product of aluminum extraction process and is present at the $\mathrm{mg} \mathrm{kg}^{-1}$ level both in coal fly ash and in alumina. Hence, a preliminary screening procedure applicable to both types of samples would help in selecting a suitable lot for extraction that yields economic benefits.

Most of the recent papers on coal fly ash are dedicated to protect the environment from toxic constituents or the bulk recovery of the precious metal from coal fly ash. ${ }^{89}$ Zhao et. al. ${ }^{7}$ reported sulfuric acid leaching of $\mathrm{Ga}$ from coal fly ash for the subsequent sequential recovery of Ga using P507 and Cyanex 272. Gutiérrez et. al. ${ }^{10}$ reported leaching of $\mathrm{Ga}$ with $\mathrm{HCl}$ for sequential extraction using Amberlite LA-2 and LIX 54N. Different acid extractions are carried out with the ultimate aim of bulk extraction using foam, Cyanex, phosphate-based extractions, etc.

Gallium is determined by instrumental techniques such as atomic absorption spectrometry (AAS), inductively coupled plasma optical emission spectrometry (ICP-OES) and inductively coupled plasma mass spectrometry (ICP-MS). Direct determination of Ga by these techniques is hampered by the matrix elements that affect recovery and precision, and also the restriction on total dissolved salts in the sample solution for analysis by ICP. Slurry sampling electrothermal-AAS is the simplest method for the determination of $\mathrm{Ga}$ in coal fly ash and does not require any sample treatment. However, the relative standard deviations (RSD) reported are higher despite the fact that quantifications are carried out against aqueous standard calibration since there is no matrix effect. ${ }^{11}$ Solvent extractions are extensively used for the extraction of $\mathrm{Ga}$ from $6 \mathrm{M}$ to $9 \mathrm{M} \mathrm{HCl}$ solution since $\mathrm{Ga}$ forms anionic $\mathrm{GaCl}_{4}$ at higher acidities. ${ }^{12-14}$ It requires total dissolution of the sample and also uses toxic organic solvents, such as isopropyl ether, diethyl ether, acetylacetone, 5, 4-methylpentan-2-ol, tributyl phosphate, etc.

Recently, the ultrasonic assisted dispersive liquid-liquid microextraction method was developed for the solvent extraction of $\mathrm{Ga}$ for its determination in vanadium titanium magnetite. ${ }^{15}$ Similarly, the determination of Ga in alumina is also important to recover the precious metal. Gallium in $\mathrm{Al}$ is determined along with other elements after separation of aluminum from alumina solution by precipitation for its determination by ICP-OES. ${ }^{16}$ Multi-stage leaching steps are reported using $\mathrm{HNO}_{3} / \mathrm{HF} / \mathrm{HClO}_{4}$ and Zheng Fang reported an $\mathrm{HCl}$ leach method with fewer recoveries. ${ }^{7,17}$ A simpler procedure with easily adaptable steps and applicable to both CFA and alumina is useful for preliminary screening of the different sample lots for the recovery of Ga.

The aim of the present work was to develop a simple leaching method for the preliminary screening of coal fly ash, alumina and other samples for Ga prior to large-scale recovery. Conditions for the quantitative recovery and analysis of different coal fly ash samples, alumina and a sediment sample are reported, along with a red mud sample.

\section{EXPERIMENTAL}

\section{Instruments}

An inductively coupled plasma optical emission spectrometer (ICP-OES), Model ULTIMA 2, Horiba Jobin Yvon, France, equipped with a concentric pneumatic nebulizer and cyclonic spray chamber, was used for all measurements. The spectrometer is equipped with a Czerny-Turner monochromator using a 2400 grooves/mm holographic grating. The wavelength $(294.364 \mathrm{~nm})$ selected for Ga was based on sensitivity and lack of spectral interference.

\section{Reagents and samples}

Analytical reagent grade chemicals were used throughout. $\mathrm{HCl}$, $\mathrm{HNO}_{3}, \mathrm{H}_{2} \mathrm{SO}_{4}$ and $\mathrm{HF}$ were procured from Merck, India. Milli-Q water (Millipore Corporation, USA) with $18 \mathrm{M} \Omega \mathrm{cm}$ resistivity was used for the preparation of all solutions. The stock standard solution (1000 $\left.\mathrm{mg} \mathrm{L}^{-1}\right)$ of Ga was procured from Merck, Germany.

The coal fly ash samples were obtained from thermal power plants. The alumina and red mud samples were obtained from a local aluminum producer. A sediment was used as a candidate for reference material, and the value reported is recommended by the producer by adopting a different procedure. All samples were processed as received.

\section{Analytical procedure}

An accurately weighed sample $(0.25 \mathrm{~g})$ was taken into a PFA container with screw cap. Added were $1 \mathrm{~mL}$ each of $\mathrm{H}_{2} \mathrm{SO}_{4}, \mathrm{HNO}_{3}$ and $0.5 \mathrm{~mL} \mathrm{HF}$, then left standing overnight or heated on a hot plate at about $100{ }^{\circ} \mathrm{C}$ for $1 \mathrm{~h}$ in closed conditions. After opening the screw cap, the acids ( $\mathrm{HF}$ and $\mathrm{HNO}_{3}$ ) were evaporated on a hot plate. The same can also be carried out on a platinum crucible. In such case, it can be heated until the appearance of thick $\mathrm{H}_{2} \mathrm{SO}_{4}$ fumes. After cooling, $1 \mathrm{~mL} \mathrm{HCl}$ was added to the residue, heated for about $5 \mathrm{~min}$ and diluted with Milli-Q water to $25 \mathrm{~mL}$ along with the undissolved solids. The same procedure was applied for all samples. Blank solutions were also prepared as above, excluding the sample. For only the coal fly ash and red mud samples, a combination of either $\mathrm{HCl} / \mathrm{HF}$ or $\mathrm{HNO}_{3} / \mathrm{HF}$ was used for the same quantity of sample, then following the same analytical procedure as above.

\section{Complete dissolution of coal fly ash and sediment}

To $0.25 \mathrm{~g}$ of sample taken into a platinum crucible, $1 \mathrm{~mL} \mathrm{H}_{2} \mathrm{SO}_{4}$ and $2 \mathrm{~mL} \mathrm{HF}$ were added and left standing overnight. HF was evaporated on a hot plate until $\mathrm{H}_{2} \mathrm{SO}_{4}$ fumes appeared. To the residue, $25 \mathrm{~mL} \mathrm{HCl}$ was added and diluted to $50 \mathrm{~mL}$ with Milli-Q water which resulted in a clear sample solution. If required, additional $\mathrm{HCl}$ was added and diluted to a higher volume. In case of the NIST coal fly ash sample and to ensure the complete 
dissolution of the very minute amount of residue left, it was fused with lithium metaborate and dissolved in a minimum amount of $\mathrm{HCl}$, then was added to the sample solution.

\section{Solvent extraction of gallium}

Ga in sample solutions taken in $6 \mathrm{M} \mathrm{HCl}$ was extracted into diethyl ether with equal volumes of aqueous and organic layers. Ga extracted into diethyl ether was stripped back into $0.01 \mathrm{M} \mathrm{HCl}$, evaporated on a water bath to volatilize residual diethyl ether, and analyzed by ICP-OES. The blank solution was also prepared as above.

\section{RESULTS AND DISCUSSION}

Gallium does not have its own ore and is present at trace levels in bauxite, an aluminum ore. Hence, Ga is extracted from the byproduct (obtained at an aluminum industry facility) or from other sources such as coal fly ash where it is present at the tens of $\mathrm{mg}$ $\mathrm{kg}^{-1}$ level. Lots containing higher concentrations of $\mathrm{Ga}$ are preferred for better yield. Hence, secondary sources of Ga need to be analyzed for Ga prior to bulk extraction. Direct determination of $\mathrm{Ga}$ from these samples after total dissolution is difficult by instrumental techniques for want of sensitivity and also due to matrix interferences. For the determination of $\mathrm{Ga}$, solvent extraction is normally adopted to pre-concentrate the analyte, while simultaneously reducing matrix interferences. However, the procedure is tedious as it involves total dissolution of the sample, followed by solvent extraction using toxic organic solvents. Moreover, residual organic solvents will extinguish the plasma if analysis is carried out by ICP-based techniques. Evaporation of the residual solvent is an additional step. Acid leaching is a better alternative to solvent extraction. Though leaching methods with different combinations of acids are reported, they either result in fewer recoveries or are used for bulk extraction.

\section{Acid Leaching of Gallium}

Initially, leaching of $\mathrm{Ga}$ from coal fly ash was reported by using $7 \mathrm{M} \mathrm{H}_{2} \mathrm{SO}_{4}$. However, the recovery of $\mathrm{Ga}$ was found to be very poor, $<5 \%$. Hence, a combination of acids for leaching was attempted with coal fly ash, obtained from the National Thermal Power Corporation (NTPC), by oxidizing mineral acids, $\mathrm{H}_{2} \mathrm{SO}_{4}$ and $\mathrm{HNO}_{3}$ for initial attack of the samples, and resulting in very poor recovery of $\mathrm{Ga}(30 \%)$. Based on previous experience and to increase recovery, a small amount of HF was added. ${ }^{18,19}$ It was found that addition of $100 \mu \mathrm{L} \mathrm{HF}$ improved the recovery of Ga to $60 \%$ (for $0.25 \mathrm{~g}$ of CFA). Hence, HF was optimized ranging from 100 to $600 \mu \mathrm{L}$ for $0.25 \mathrm{~g}$ of coal fly ash sample. The recoveries are calculated based on true value of Ga obtained by ICP-OES (14.9 $\mathrm{mg} \mathrm{kg}^{-1}$ ). As shown in Table 1, the recovery of Ga increased with the HF concentration and maximum recovery was obtained between 400 to $500 \mu \mathrm{L}$. For further studies, the concentration of $500 \mu \mathrm{L} \mathrm{HF}$ was used.
Table 1. Amount of HF Required to Leach Ga from $250 \mathrm{mg}$ of Coal Fly Ash (CFA) in Presence of $1 \mathrm{~mL}$ each $\mathrm{H}_{2} \mathrm{SO}_{4}$ and $\mathrm{HNO}_{3}$

\begin{tabular}{cccc}
\hline $\begin{array}{c}\text { Sample } \\
\text { No. }\end{array}$ & $\begin{array}{c}\text { Volume of } \\
\mathbf{4 8 \%}(\mathbf{w} / \mathbf{v}) \mathbf{H F}(\boldsymbol{\mu L})\end{array}$ & $\begin{array}{c}\text { Concentration of Ga in } \\
\text { NTPC CFA }\left(\mathbf{m g ~ k g}^{-\mathbf{1}}\right)\end{array}$ & $\begin{array}{c}\text { Recovery } \\
(\mathbf{\%})^{\mathbf{a}}\end{array}$ \\
\hline $\mathbf{1}$ & 100 & 9.0 & 60.4 \\
$\mathbf{2}$ & 200 & 12.6 & 84.5 \\
$\mathbf{3}$ & 300 & 13.5 & 90.6 \\
$\mathbf{4}$ & 400 & 15.1 & 101.0 \\
$\mathbf{5}$ & 500 & 15.2 & 102.0 \\
$\mathbf{6}$ & 600 & 13.5 & 90.6 \\
\hline
\end{tabular}

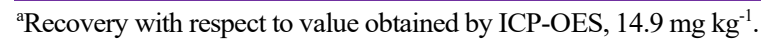

Table 2. Comparison of Concentrations Obtained by Present and Solvent Extraction Methods

\begin{tabular}{lcc}
\hline Sample & Leaching method & Solvent extraction \\
\hline NTPC-CFA & $15.3 \pm 0.3$ & $14.1 \pm 1.1$ \\
IMMT-CFA & $44.4 \pm 2.1$ & $45.0 \pm 1.2^{\mathrm{a}}$ \\
NIST-CFA 1633b & $57.5 \pm 1.8$ & $55.2 \pm 4.0^{\mathrm{a}}$ \\
GSI Sediment (SSS1) & $22.4 \pm 2.3$ & $24.4 \pm 3.9^{\mathrm{b}}$ \\
Alumina & $38.0 \pm 1.0$ & $39.0 \pm 1.0$ \\
\hline
\end{tabular}

Uncertainties are expressed as standard deviation of three measurements.

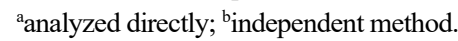

Along with $1 \mathrm{~mL}$ each of $\mathrm{H}_{2} \mathrm{SO}_{4}$ and $\mathrm{HNO}_{3}, 500 \mu \mathrm{L} \mathrm{HF}$ was added to $0.25 \mathrm{~g}$ sample for quantitative leaching of Ga. Nitrate vapors appeared after the addition of HF. All of the acids, except $\mathrm{H}_{2} \mathrm{SO}_{4}$, were evaporated and $1 \mathrm{~mL} \mathrm{HCl}$ was added since $\mathrm{Ga}$ has an affinity to $\mathrm{HCl}$. The leach and the solid were transferred into a polypropylene (PP) vial and diluted to $25 \mathrm{~mL}$ with Milli-Q water for analysis by ICP-OES. External calibration was used for quantification. As there is no coal fly ash CRM available and certified for $\mathrm{Ga}$, a CRM candidate sediment material was analyzed, whose $\mathrm{Ga}$ concentration is indicated by the CRM producer, for accuracy. The concentration obtained by the present method and the same reported by the CRM producer was within the uncertainty mentioned (Table 2).

Since the method was validated for sediment, a similar silicate matrix, the method was applied to three coal fly ash samples and one alumina sample. The alumina sample was selected in order to explore the possibility of applying the method to alumina also. The concentrations obtained are shown in Table 2. The values obtained on real world samples are validated by using the solvent extraction method after total dissolution. For total dissolution of coal fly ash, normally $\mathrm{NaOH}$ fusion or microwave digestion methods are adopted to ensure complete dissolution. In this study, a simple method was adopted using a mixture of acids and a hot plate for heating as mentioned in the experimental section.

For solvent extraction, sample solutions of coal fly ash and alumina taken in $6 \mathrm{M} \mathrm{HCl}$ were used. A suitable aliquot was taken and $\mathrm{Ga}$ extracted with an equal volume of diethyl ether. Gallium from the ether layer is back-extracted into $0.01 \mathrm{M} \mathrm{HCl}$ solution. The solution was analyzed for Ga after evaporating the ether, since the presence of an organic solvent will extinguish the plasma during ICP-OES analysis. The results obtained by solvent extraction 
Table 3. Comparison of Concentrations of Ga Obtained by Leaching with Different Acids

\begin{tabular}{lccc}
\hline \multirow{2}{*}{ Sample } & \multicolumn{2}{c}{ Leaching method } & \multirow{2}{*}{$\begin{array}{c}\text { Total } \\
\text { dissolution }\end{array}$} \\
\cline { 2 - 3 } & $\mathrm{HCl}+\mathrm{HF}$ & $\mathrm{HNO}_{3}+\mathrm{HF}$ & $14.9 \pm 0.1$ \\
NTPC-CFA & $15.6 \pm 0.4$ & $15.3 \pm 0.3$ & $15.2 \pm 4.0$ \\
NIST-CFA 1633b & $45.7 \pm 2.0$ & $49.5 \pm 0.7$ & $55.2 \pm 0.9$ \\
GSI Sediment (SSS1) & $15.4 \pm 0.8$ & $16.8 \pm 0.3$ & $24.4 \pm 3.9^{\mathrm{a}}$ \\
Alumina & $40.0 \pm 2.0$ & $31.5 \pm 0.5$ & $39.0 \pm 1.0$ \\
Redmud & $95.0 \pm 2.3$ & $89.6 \pm 3.0$ & $98.0 \pm 3.0$ \\
\hline
\end{tabular}

Uncertainties are expressed as standard deviation of three measurements.

are close to the developed method with a $95 \%$ confidence level according to the Student's t-test. The results are shown in Table 2. The limit of detection, calculated as the signal equal to three times the standard deviation (six measurements) + blank, was $0.45 \mathrm{mg}$ $\mathrm{Kg}^{-1}$. The concentration of $\mathrm{Ga}$ in the samples analyzed was in the range of $15-98 \mathrm{mg} \mathrm{kg}^{-1}$.

In order to reduce the number of acids for leaching $\mathrm{Ga}$, a combination of $\mathrm{HCl} / \mathrm{HF}$ and $\mathrm{HNO}_{3} / \mathrm{HF}$ was tested. It was found that the recoveries are quantitative in case of coal fly ash and red mud. Red mud was considered since the above procedure could not be applied due to the complete dissolution in mixed acids. The procedure was further simplified by using either of the acid combinations; however, it is suitable only for coal fly ash and red mud (Table 3).

\section{CONCLUSIONS}

A simple method is reported using mixed acid leaching of Ga from coal fly ash, sediment and alumina. The leach solution was analyzed for Ga by ICP-OES. The wide scope of the method, applicable to silicate matrices and also alumina, makes it a promising application for preliminary screening of $\mathrm{Ga}$. The accuracy of the method was verified by analyzing sediment samples by an independent laboratory using an independent method. Validation of the method was carried out by solvent extraction. The method is further simplified by reducing one acid, however it is suitable only for coal fly ash and red mud. The proposed method is simple and can be adopted for screening samples for Ga content.

\section{AUTHOR INFORMATION}

\section{Corresponding Author}

* A. C. Sahayam

Email address: sahayam@barc.gov.in

Notes

The authors declare no competing financial interest.

\section{ACKNOWLEDGMENTS}

The authors would like to thank Dr. Sanjiv Kumar, Head, NCCCM, for his support and encouragement.

\section{REFERENCES}

1. R. R. Moskalyk, Miner. Eng., 2003, 16, 921-929. https://doi: 10.1016/j.mineng.2003.08.003

2. F. A. de Santana, J. T.P. Barbosa, G. D. Matos, M. G.A. Korn, and S. L.C. Ferreira, Microchem. J., 2013, 110, 198-201. https://dx.doi.org/10.1016/j.microc.2013.03.011

3. M. Frenzel, M.P. Ketris, T. Seifert, and J. Gutzmer, Resour. Policy, 2016, 47, 38-50. https:// doi: 10.1016/j.resourpol.2015.11.005

4. R.S. Blissett and N.A. Rowson, Fuel, 2012, 97, 1-23. https://doi.org/10.1016/j.fuel.2012.03.024

5. https://en.wikipedia.org/wiki/Electricity_generation

6. https://www.statista.com/statistics/530569/installed-capacity-ofcoal-power-plants-in-selected-countries/

7. Z. Zhao, L. Cui, Y. Guo, H. Li, and F. Cheng, Chem. Eng. J., 2020, 381, 122699. https://doi.org/10.1016/j.cej.2019.122699

8. R. N. Lieberman, Y. Knop, X. Querol, N. Moreno, C. Mũnoz-Quirós, Y. Mastai, Y. Anker, and H. Cohen, J. Hazard. Mater, 2018, 344, 1043-1056. https://doi: 10.1016/j.jhazmat.2017.11.047

9. A. R. K. Gollakota, V. Volli, and C.-M. Shu, Sci. Total Environ., 2019, 672, 951-989. https://doi.org/10.1016/j.scitotenv.2019.03.337

10. B. Gutiérrez, C. Pazos, and J. Coca, Waste Manag. Res., 1997, 15, 371-382. https://doi.org/10.1177/0734242X9701500405

11. X.-Q. Shan, W. Wang, and B. Wen, J. Anal. At. Spectrom., 1992, 7, 761-764. https://doi.org/10.1039/JA9920700761

12. N. H. Nachtrieb and R. E. Fryxell, J. Am. Chem. Soc., 1949, 71, 4035- 4039. https://doi.org/10.1021/ja01180a047

13. S. V. Mahamuni, P. P. Wadgaonkar, and M. A. Anuse, J. Serb. Chem. Soc., 2010, 75, 1099-1113. https://doi:10.2298/ JSC090630072M

14. I. Mihaylov and P. A. Distin, Hydrometallurgy, 1992, 28, 13-27. https://doi.org/10.1016/0304-386X(92)90062-5

15. T. Cui, X. Zhu, L. Wu, and X. Tan, Microchem. J., 2020, 157, 104993. https://doi.org/10.1016/j.microc.2020.104993

16. A. L. Souza, S. G. Lemos, and P. V. Oliveira, Spectrochim. Acta B, 2011, 66, 383-388. https://doi.org/10.1016/j.sab.2011.03.001

17. Z. Fang and H. D. Gesser, Hydrometallurgy, 1996, 41, 187-200. https://doi.org/10.1016/0304-386X(95)00055-L

18. C.-Y. Kuo, S.-J. Jiang, and A. C. Sahayam, J. Anal. At. Spectrom., 2007, 22, 636-641. https://doi.org/10.1039/B701112A

19. P. Mamatha, G. Venkateswarlu, A. V. N. Swamy, and A. C. Sahayam, Anal. Methods, 2014, 6, 9653-9657. https://doi.org/10.1039/C4AY01914H 